\title{
Modeling and optimization of 2-Chlorophenol degradation using ultrasound assisted Fe304@Ti02: Central Composite Design- Genetic Algorithm approach
}

Ali Azari ( $\sim$ Azari.hjh@gmail.com )

Tehran University of Medical Sciences

Sina Dobaradaran

Bushehr University of Medical Sciences

Mohammad Raeesi

Tehran University of Medical Sciences

Seyed Yaser Hashemi

Fasa University of Medical Sciences

Marylou Delatte

University of Tehran

Mansour Baziar

Birjand University of Medical Sciences

Saeid Dashti

Birjand University of Medical Sciences

\section{Research Article}

Keywords: Sonocatalytic degradation, Modelling and optimization, 2-Chlorophenol, CCD-GA, Fe3O4 -TiO2

Posted Date: April 22nd, 2021

DOI: https://doi.org/10.21203/rs.3.rs-444808/v1

License: (c) (i) This work is licensed under a Creative Commons Attribution 4.0 International License. Read Full License 


\section{Abstract}

In this study, the ultrasound-catalyst hybrid system was applied for degradation of 2-chlorophenol (2-CP) from aquatic environment. The produced catalyst was characterized by transmission electron microscopy, scanning electron microscopy, X-ray scattering, vibration magnetometer and nitrogen adsorption/desorption analysis, showing the successful synthesize of the coreshell structure of magnetic $\mathrm{TiO}_{2}$. A Central Composite Design (CCD) was applied in MATLAB software to investigate the effective parameters in degradation and evaluate the removal of 2-CP by M-TiO2-US system. Kinetics, intermediate products and catalyst reusability were determined under optimal conditions. The results indicated that $\mathrm{pH}$ of 4.413 , catalyst dosage of $0.733 \mathrm{~g} / \mathrm{L}, 2-\mathrm{CP}$ concentration of $2.549 \mathrm{mg} / \mathrm{L}$, ultrasound power of $55.605 \mathrm{~W} / \mathrm{L}$ had the maximum degradation efficiency $(97.776 \%)$ and $\mathrm{pH}$ was assigned as the most effective parameter for the degradation of 2-CP. Superoxide and hydroxyl radicals were considered as the main cause of 2-CP degradation. Catalyst stability was investigated in 5 replicates and verified. The overall results show that the $\mathrm{M}-\mathrm{TiO}_{2}$ and US hybrid system has promising performance in the degradation of 2-chlorophenol and has the ability to use on a larger scale.

\section{Highlights}

1. The ultrasound-assisted magnetic degradation is an effective system for 2-Chlorophenol removal.

2. Superoxide and hydroxyl radicals were considered as the main cause of 2-CP degradation.

3. $\mathrm{Fe}_{3} \mathrm{O}_{4} @ \mathrm{TiO}_{2}$ could keep its performance to at least the 5th cycle.

4. Best productivity (77\%) were $\mathrm{pH}: 4.41$, catalyst dose: $0.73 \mathrm{~g} / \mathrm{L}$, ultrasound frequency: $55.60 \mathrm{~W} / \mathrm{L}$ and 2-CP concentration: 2.55 $\mathrm{mg} / \mathrm{L}$

5. Data well fitted with First-order kinetic model.

\section{Introduction}

Chlorophenols (CPs) group compounds such as 2-chlorophenol, 4-chlorophenol, and 2-4-chlorophenol have a severely adverse effect on human health and the environment. Among CPs, the study of 2-chlorophenol (2-CP) due to high toxicity, carcinogenicity, environmental stability, and low biodegradability has been increasingly considered by researchers and has been considered as a top priority pollutant of the US Environmental Protection Agency [1]. Industrial activities such as oil refining, chloro-based pesticide hydrolysis, and chlorine reaction during the disinfection of urban water treatment systems with humic acid are the primary sources of 2-chlorophenol production [2]. Exposure to 2-CP can cause severe detrimental effects on the endocrine glands and reproductive organs, even at very low concentration [3]. Eye and skin irritation, headache, liver damage, and irregular heartbeat are other side effects of 2-CP exposure [4]. Based on the reported studies on high concentrations of the 2-CP, common biological treatment strategies are considered less efficient techniques; thereby, degradation of 2-CP with the photocatalytic method, electrocatalytic method, Fenton oxidation, and most recently chemical ultrasonic methods have been attracted more attention $[5,6]$.

Application of titanium dioxide $\left(\mathrm{TiO}_{2}\right)$ as photocatalyst due to unique characteristics such as chemical stability, availability, and low cost has been known as the proper technology for the removal of organic contaminants. However, the separation and reuse of $\mathrm{TiO}_{2}$ have always been a setback in its practical implementation [7]. Studies in recent decades have reported stabilizing $\mathrm{TiO}_{2}$ on magnetic materials such as $\mathrm{Fe}_{3} \mathrm{O}_{4}$ as a solution for resolving the separation problem. Barbosa et al., Ebrahimi et al., and Golsefidi et al. have described the synthesis of a magnetic composite as a solution for the separation and recovery of $\mathrm{TiO}_{2}$, citing economic efficiency, high separation rate, non-toxicity and simplicity of the process [8-10]. On the other hand, adsorption of intermediate degradation and condensation products by $\mathrm{Fe}_{3} \mathrm{O}_{4}$ adjacent to $\mathrm{TiO}_{2}$ nanoparticles, causes the degradation process to continue until the complete removal of the contaminant. Implementation in the industrial scales still faces two obstacles. First, due to the dark nature of industrial wastewater, UV radiations cannot permeate through the catalyst and therefore impede the production of free radicals. The second problem is the aggregation of ferrous nanoparticles and decreasing the contact surface with the contaminant [11]. Using ultraviolet radiation with very high intensity can sometimes solve the first problem, which leads to high energy consumption and expensive equipment. Therefore, the use of appropriate alternatives that can address both

Page $2 / 21$ 
issues is subject to be considered. The use of ultrasound waves instead of UV radiation has been suggested in many studies. In addition to the ability to generate significant amounts of electron-hole pairs and $\mathrm{OH}$ radicals, ultrasound waves also accelerate the movement of electrons in the $\mathrm{TiO}_{2}$ crystal structure. Moreover, ultrasound waves increase the pressure by forming microbubbles in the aqueous solution, which in turn has a significant effect on the production of $\mathrm{OH}$ radicals and completes the process of contaminant degradation [12]. On the other hand, the propagation of ultrasound waves scatters (uniformly distributes) the synthesized nanocomposite in the solution and prevents it from aggregation, which leads to an increase in the surface area of the catalyst and the degradation of the contaminant [13].

Nowadays, the use of statistical models and experiment design software has reduced the number of samples, costs, energy, raw material consumption, and waste production. In this study, MATLAB software has been used to investigate this challenge [14]. The aim of this study was to (1) synthesis and evaluate the characteristics of a magnetic $\mathrm{TiO}_{2}$ nanocomposite $\left(\mathrm{M}-\mathrm{TiO}_{2}\right)$. (2) investigating the ability of $\mathrm{M}-\mathrm{TiO}_{2}-\mathrm{US}$ in the removal of 2-CP by considering $\mathrm{pH}, \mathrm{M}-\mathrm{TiO}_{2}$ dosage, 2-CP concentration, and US wavelength as the effective degradation factors. (3) prediction of degradation of contaminant by MATLAB software and comparison of the predicted results with experimental data. (4) Optimization of the degradation conditions by genetic algorithm perspective and its comparison with laboratory results. And (5) determination the TOC degradation rate under optimal conditions.

\section{Experimental}

\subsection{Chemicals and materials}

Titanium isopropoxide $\left(\mathrm{Ti}\left[\mathrm{OCH}\left(\mathrm{CH}_{3}\right)_{2}\right]_{4},>99.99 \%\right)$, 2-chlorophenol, hydroquinone ( $\left.\mathrm{HQ}\right)$, and benzoquinone were purchased from Sigma-Aldrich Corporation (USA). Iron(II) chloride and Iron(III) chloride $\left(\mathrm{FeCl}_{2}\right.$ and $\left.\mathrm{FeCl}_{3},>99.99 \%\right)$, sodium hydroxide ( $\mathrm{NaOH}$, $\geq 97.0 \%$ ), ethanol $\left(\mathrm{CH}_{3} \mathrm{CH}_{2} \mathrm{OH}, \geq 95.0 \%\right)$, acetic acid $\left(\mathrm{CH}_{3} \mathrm{CO}_{2} \mathrm{H}\right)$, glycol $\left(\mathrm{H}_{(}\left(\mathrm{OCH}_{2} \mathrm{CH}_{2}\right)_{n} \mathrm{OH}\right)$, urea $\left(\mathrm{NH}_{2} \mathrm{CONH}_{2}\right)$, and analytical grade nitric acid $\left(\mathrm{HNO}_{3}\right)$ were purchased from Merck company (USA). All the standard solutions were prepared using distilled water. Initial $\mathrm{pH}$ of the solution was adjusted by 1 normal $\mathrm{HCL}$ and $\mathrm{NaOH}$. Separation of the composite from the solution was conducted by a cubic magnet $(40 \times 50 \times 10 \mathrm{~cm})$ with a magnetic field of 3000 Gauss.

\subsection{Instruments}

High-performance liquid chromatography (HPLC, Cecil 4100 power stream Interface, England) equipped with a UV light detector (CE 4900) was used to determine the concentration of 2-CP. The mobile phase (methanol: water $=80: 20, v / v$ ) with an injection flow rate of $1.0 \mathrm{~mL} \mathrm{~min}{ }^{-1}$, injection volume of $20 \mu \mathrm{L}$, column temperature $30^{\circ} \mathrm{C}$, and detection wavelength of $230 \mathrm{~nm}$ was considered as the operation conditions of HPLC. In order to determine the amount of intermediate and final products of degradation an Agilent 6890 gas chromatograph with an HP-5MS capillary column (30 m, $300 \mathrm{~mm}$ internal diameter) equipped with Agilent 5973 mass detection wavelength was employed. Helium gas was used as the carrier gas at a constant flow of 1.0 $\mathrm{mL} \mathrm{min}{ }^{-1}$ and the oven temperature was kept constant at $300^{\circ} \mathrm{C}$ for this part of the study. Also, initial and final TOC was determined by TOC analyzer at optimized conditions.

\subsection{Synthesize of $\mathrm{Fe}_{3} \mathrm{O}_{4}-\mathrm{TiO}_{2}$}

Iron oxide nanoparticles were synthesized based on Azari et al. reports [15]. For this purpose, co-precipitation method of iron II and III chlorides was used in the presence of sodium hydroxide. The final product was extracted using a magnet and washed several times with deionized water and methanol. Subsequently, the final product was dried under $\mathrm{N}_{2}$ gas in the oven with a temperature of $80^{\circ} \mathrm{C}$. To synthesize $\mathrm{M}-\mathrm{TiO}_{2}$ composite, First $6.8 \mathrm{~mL}$ of titanium isopropoxide $\left(\mathrm{Ti}\left[\mathrm{OCH}\left(\mathrm{CH}_{3}\right)_{2}\right]_{4}\right)$ and acetic acid $\left(\mathrm{HNO}_{3}\right)$ was solved in $60 \mathrm{~mL}$ of ethanol $\left(\mathrm{CH}_{3} \mathrm{CH}_{2} \mathrm{OH}\right)$. Then, $1.5 \mathrm{~g}$ of the iron oxide synthesized in the previous step was added to the above solution and placed in an ultrasonic device for 15 minutes to obtain a homogeneous mixture. In the next step, $2.4 \mathrm{~g}$ of Polyethylene glycol $\left(\mathrm{H}_{(}\left(\mathrm{OCH}_{2} \mathrm{CH}_{2}\right)_{\mathrm{n}} \mathrm{OH}\right)$ and urea $\left(\mathrm{NH}_{2} \mathrm{CONH}_{2}\right)$ was added to the solution and mixed thoroughly for 60 min. Finally, the mixture was transferred to an autoclave at $180^{\circ} \mathrm{C}$ for 8 hours. $\mathrm{M}-\mathrm{TiO}_{2}$ magnetic nanocomposite was washed several times with ethanol and dried under $\mathrm{N}_{2}$ gas in the oven at a temperature of $80^{\circ} \mathrm{C}$ in 12 hours [16]. Characterization of the synthesized catalyst was investigated by scanning electron microscopy (SEM), transmission electron microscopy (TEM), X-ray diffraction 
analysis (XRD), and vibrating sample magnetometer (VSM) to obtain comprehensive information from the synthesized catalyst. To investigate the active surface area, distribution and pore size of the synthesized samples Brunauer-Emmett-Teller (BET) and Barret-Joyner-Helenda methods were applied.

\subsection{Degradation experiments}

The degradation ability of 2-CP was assigned by adding specific amount of the catalyst in various concentration of the contaminant at different $\mathrm{pH}$ values. Before the propagation of the ultrasound wave, the solution of 2-CP and catalyst was mixed by a mechanical stirrer (without exposure to ultrasound waves) to reach the adsorption-desorption equilibrium on the surface of the catalyst and also to remove the effect of the adsorption during the sonocatalytic process.

Degradation experiments were performed in the mentioned reactor with predetermined values of $\mathrm{pH}$, catalyst dosage, concentration of the contaminant, and ultrasound wavelength. Propagation of the ultrasound wave was conducted at specific time intervals. After that, the catalyst was separated from the solution by a magnet and the residual concentration of 2-CP in the

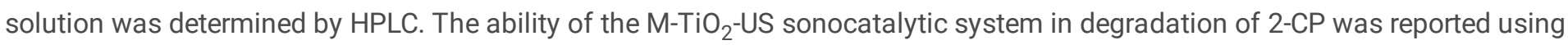
the following equation:

$$
\text { Degradation } \%=\left(\frac{\mathrm{C}_{0}-\mathrm{C}_{\mathrm{e}}}{\mathrm{C}_{0}}\right) \times 100
$$

The kinetic of the process was evaluated and reported after the optimization of the degradation conditions. Due to the fact that most researches use the first-order kinetic to model the degradation of organic and inorganic pollutants, in this study, first-order kinetic was used to investigate the rate of degradation of 2-CP. The following equation represents first-order kinetic: Where $\mathrm{C}_{0}$ and $\mathrm{C}_{\mathrm{e}}$ are the initial and residual concentrations of $2-\mathrm{CP}\left(\mathrm{mg} \mathrm{L}^{-1}\right)$, respectively.

$$
\ln \left(\frac{\mathrm{C}_{0}}{\mathrm{C}_{\mathrm{e}}}\right)=\mathrm{K}_{\mathrm{app}} \times \mathrm{t}
$$

Where $\mathrm{K}_{\mathrm{app}}$ represents the rate of the reaction $\left(\mathrm{min}^{-1}\right), \mathrm{C}_{0}$ and $\mathrm{Ce}$ are the initial and residual concentrations of the contaminants $\left(\mathrm{mg} \mathrm{L}^{-1}\right)$, and $\mathrm{t}$ is the time (min).

\subsection{Statistical design}

To investigate the effect of the independent parameters on the degradation of 2-CP, a 2015 version of the MATLAB software based on the central composite design (CCD) was applied. Table 1 shows the independent variables and a summary of the input data. In this study a total of 21 experiments were conducted. The analysis of variances (ANOVA) was applied to evaluate the significance effect of the variables on corresponding responses. SSE and RMSE errors were used to investigate the ability of the studied software to predict the results of degradation conditions compared to the actual conditions. The small difference between the actual and predicted results and low levels of errors indicate the great ability of the model to examine and analyze the input data. Genetic algorithm was applied to optimize the effective parameters in the 2-CP degradation.

Table 1. Independent variables and their range and levels of experimental values

\begin{tabular}{|llllllll|}
\hline Symbol & Parameters examined & unit & $\mathbf{a}-$ & $\mathbf{a}+$ & $-\mathbf{1}$ & $\mathbf{+ 1}$ & $\mathbf{0}$ \\
\hline $\mathbf{X 1}$ & $\mathrm{pH}$ & - & 3 & 11 & 5 & 9 & 7 \\
$\mathbf{X 2}$ & Catalyst dose & $\mathrm{g} / \mathrm{L}$ & 0.05 & 1 & 0.2875 & 0.7625 & 0.525 \\
\hline $\mathbf{X 3}$ & 2-CP concentration & $\mathrm{mg} / \mathrm{L}$ & 1 & 5 & 2 & 4 & 3 \\
\hline $\mathbf{X} 4$ & Ultrasound power & $\mathrm{W} / \mathrm{L}$ & 25 & 100 & 43.75 & 81.25 & 62.5 \\
\hline $\mathbf{y}$ & Degradation rate & Percentage & 0 & 100 & - & - & - \\
\hline
\end{tabular}

Page $4 / 21$ 
The proposed statistical design by the studied software to investigate the effect of variables on the degradation efficiency of 2-CP can be seen in Table 2.

Table 2. Degradation process steps based on RSM-CCD

\begin{tabular}{|c|c|c|c|c|c|c|}
\hline & & Factor 1 & Factor 2 & Factor 3 & Factor 4 & Response 1 \\
\hline Std & Run & $\mathrm{A}: \mathrm{pH}$ & B: Catalyst dose & C:2-CP Con. & D:US power & Removal \\
\hline & & & $g / L$ & $\mathrm{mg} / \mathrm{L}$ & $W / L$ & $\%$ \\
\hline 12 & 1 & 7 & 1 & 3 & 62.5 & 84.25 \\
\hline 8 & 2 & 5 & 0.2875 & 2 & 43.75 & 79.6875 \\
\hline 6 & 3 & 5 & 0.2875 & 4 & 43.75 & 65.8125 \\
\hline 21 & 4 & 7 & 0.525 & 3 & 62.5 & 84 \\
\hline 20 & 5 & 7 & 0.525 & 3 & 62.5 & 84 \\
\hline 5 & 6 & 9 & 0.2875 & 2 & 81.25 & 59.6875 \\
\hline 7 & 7 & 5 & 0.7625 & 4 & 81.25 & 68.8125 \\
\hline 11 & 8 & 7 & 0.05 & 3 & 62.5 & 54.25 \\
\hline 1 & 9 & 9 & 0.7625 & 4 & 43.75 & 43.8125 \\
\hline 9 & 10 & 3 & 0.525 & 3 & 62.5 & 86.25 \\
\hline 4 & 11 & 5 & 0.7625 & 2 & 81.25 & 93.6875 \\
\hline 16 & 12 & 7 & 0.525 & 3 & 100 & 75.25 \\
\hline 18 & 13 & 7 & 0.525 & 3 & 62.5 & 84 \\
\hline 14 & 14 & 7 & 0.525 & 5 & 62.5 & 44.125 \\
\hline 13 & 15 & 7 & 0.525 & 1 & 62.5 & 64.375 \\
\hline 10 & 16 & 11 & 0.525 & 3 & 62.5 & 26.25 \\
\hline 3 & 17 & 9 & 0.2875 & 4 & 81.25 & 38.8125 \\
\hline 17 & 18 & 7 & 0.525 & 3 & 62.5 & 84 \\
\hline 2 & 19 & 9 & 0.7625 & 2 & 43.75 & 44.6875 \\
\hline 15 & 20 & 7 & 0.525 & 3 & 25 & 60.25 \\
\hline 19 & 21 & 7 & 0.525 & 3 & 62.5 & 84 \\
\hline
\end{tabular}

\section{Results And Discussion}

\subsection{Characterization of the $\mathrm{Fe}_{3} \mathrm{O}_{4}-\mathrm{TiO}_{2}$}

Fig. 1 shows the morphology and surface features of ${\mathrm{M}-\mathrm{TiO}_{2}}_{2}$ by scanning electron microscopy (SEM). In the mentioned figure, spherical structure of the catalyst with a size between 30 to $100 \mathrm{~nm}$ can be seen. The shape and size of $\mathrm{M}-\mathrm{TiO}_{2}$ was studied by transmission electron microscope (TEM) and the results are presented in Fig. 1b. TEM images shows a core-shell structure in the synthesized nanocomposite. The spherical structure of the $\mathrm{Fe}_{3} \mathrm{O}_{4}$ and $\mathrm{TiO}_{2}$ are also evident in this analysis. Determination of the crystalline structure phase of the synthesized composite was conducted using X-ray diffraction analysis (XRD) by Cu radiation in the $2 \theta=10-80^{\circ}$ and ambient temperature. Fig. $1 \mathrm{c}$ shows the XRD pattern of the synthesized catalyst. 
The resulted peaks at $24.8^{\circ}, 37.3^{\circ}, 47.6^{\circ}, 54.5^{\circ}, 55.1^{\circ}$ and $62.2^{\circ}$ correspond to (101), (004), (200), (105), (211) and (204) crystal planes based on the JCPDS no. 21-1272 standard indicated the presence of $\mathrm{TiO}_{2}$ with anatase structure. The resulted diffraction patterns showed at $2 \theta=35.6^{\circ}, 43.2^{\circ}, 57.2^{\circ}$ and $62.8^{\circ}$ from the reflection crystal planes (311), (400), (511), and (440) based on the JCPDS no. 19-629 standard indicated the presence of $\mathrm{Fe}_{3} \mathrm{O}_{4}$ in the synthesized composite structure. Magnetic and separation ability of $\mathrm{Fe}_{3} \mathrm{O}_{4}$ and $\mathrm{M}-\mathrm{TiO}_{2}$ composite was evaluated using a Vibrating-sample magnetometer (VSM) (Fig. 1d). This analysis was performed in the magnetic field range of $\pm 15 \mathrm{KOe}$ and in the saturation magnetization range of $\pm 100 \mathrm{emu} \mathrm{g}^{-1}$. The saturation magnetization for pure $\mathrm{Fe}_{3} \mathrm{O}_{4}$ was equal to $86 \mathrm{emu} \mathrm{g}^{-1}$, which indicates the high magnetic property and rapid separation ability from the aqueous solution. The saturation magnetization of the synthesized composite was $60 \mathrm{emu} \mathrm{g}^{-1}$. The decrease of the saturation magnetization in $\mathrm{M}-\mathrm{TiO}_{2}$ was due to the presence of $\mathrm{TiO}_{2}$, which has no magnetic property. However, complete separation of the synthesized composite without any residuals in the solution is observable in Fig. 1d (inner), which shows the proper ability of the synthesized catalyst for reuse purposes.

The specific surface area and porosity of $\mathrm{M}-\mathrm{TiO}_{2}$ were calculated and presented in Table 3 using the analysis of adsorptiondesorption isotherms of nitrogen gas at $77 \mathrm{~K}$ and a pressure ratio range of $0-1$.

Table 3. Adsorption and desorption analysis, porosity and volume of porosity of the studied samples and the ability to absorb each

\begin{tabular}{|lllllll|}
\hline samples & $\begin{array}{l}\text { Initial concentration } \\
(\mathbf{m g} / \mathbf{L})\end{array}$ & $\begin{array}{l}\text { removal rate } \\
(\%)\end{array}$ & $\begin{array}{l}\text { Sample dose } \\
\left(\mathbf{g ~ L}^{-1}\right)\end{array}$ & $\begin{array}{l}\text { Active level } \\
\left(\mathbf{m}^{2} \mathbf{g}^{-1}\right)\end{array}$ & Pore size $(\mathbf{n m})$ & Pore volume $\left(\mathbf{c m}^{\mathbf{3}} \mathbf{g}^{-1}\right)$ \\
\hline $\mathrm{Fe}_{3} \mathrm{O}_{4}$ & 2 & 18 & 0.25 & 83.48 & 1.432 & 0.532 \\
\hline $\mathrm{TiO}_{2}$ & 2 & 13 & 0.25 & 28 & 1.486 & 0.324 \\
\hline $\mathrm{M}^{-\mathrm{TiO}_{2}}$ & 2 & 22 & 0.25 & 101.42 & 1.695 & 0.274 \\
\hline
\end{tabular}

\section{2Influence of effective parameters on the degradation process}

Before investigating the influence of the effective parameters on sonocatalytic degradation of 2-CP with the MATLAB software, the effect of the contaminant adsorption was studied by different materials in the absence of ultrasound wave propagation. As it can be seen in Table 3, 2-CP adsorption by $\mathrm{TiO}_{2}, \mathrm{Fe}_{3} \mathrm{O}_{4}$, and $\mathrm{M}-\mathrm{TiO}_{2}$ was 18,13 , and 22 percent, respectively. The highest contaminant adsorption was related to $\mathrm{M}-\mathrm{TiO}_{2}$ which can be attributed to the high surface-active sites of the composite compared to other cases. This is despite the fact that the adsorption process of 2-CP by $\mathrm{M}-\mathrm{TiO}_{2}$ is not significant in the absence of US release and is only $22 \%$. Due to the insignificant amount of contaminant removal by the adsorption process, the whole degradation process was considered as sonocatalytic degradation. Fig. 2a-c shows the intervening effect of the studied initial parameters in the degradation process of 2-CP. As shown in Fig. 2 at higher pHs, the concentration of 2-CP does not decrease significantly, while at acidic pHs, there is a significant decrease in the contaminant concentration. It can be seen that the removal efficiency decreased by approximately $65 \%$ by increasing the $\mathrm{pH}$ from 3 to 11 . The proper performance of the sonocatalytic system in acidic conditions can be due to various reasons, such as High dissolution of iron, which can accelerate the reaction on the catalyst surface and increase the production of hydroxyl radicals. In acidic pHs, Fe (III) is mainly soluble in the solution and by contacting with ultrasound vibrations will help produce free radicals and subsequent degradation of the contaminant by a Fenton-like process. Afterward, by increasing the $\mathrm{pH}$, dimeric, oligomeric, and colloidal compounds of Fe (III) dominates its mononuclear species. Extreme vibration is required in dimeric/oligomeric or colloidal species to produce free radicals comparing to the $\mathrm{Fe}$ in the monomer state. Insufficient production of free radicals in non-monomeric species is the main difference between these species [17]. Moreover, zeta-potential was 6.8 for the synthesized catalyst. In pHs lower than $\mathrm{pH}_{\mathrm{pzc}}$, the catalyst was positively charged while in $\mathrm{pHs}>\mathrm{pH}_{\mathrm{pzc}}$, the catalyst was charged negatively. Due to the presence of phenolic compounds in the structure of 2-CP, this contaminant will have a negative charge. Therefore, the electrostatic attraction between the catalyst and the 2-CP molecules' positive surface leads to increased contact (collision) and subsequent degradation of 2-CP on the catalyst in acidic conditions. In summary, the electrostatic interaction between the catalyst (+) and 2-CP (-) with increasing and concentrating the contaminant on the catalyst and expanding the contact time between the two, is the main factor boosting the 
degradation efficiency in acidic conditions. In contrast, at high $\mathrm{pHs}\left(\mathrm{pH}>\mathrm{pH}_{\mathrm{pzc}}\right)$, negatively charged surface of the catalyst reduces the efficiency of degradation by creating an electrostatic repulsion force between the catalyst and 2-CP [18,19]. Similar results have been reported in Rashid et al. study investigating the removal of 2-CP from aqueous solution using $\mathrm{Fe}_{3} \mathrm{O}_{4} / \mathrm{SiO}_{2} /$ $\mathrm{TiO}_{2}$. Rashid reported that with increasing the $\mathrm{pH}$ from 3 to 9 , the degradation process's efficiency has decreased from 97.2 to 32.4 percent. This researcher confirms the strong dependence of the 2-CP degradation process on $\mathrm{pH}$ and attributes it to $\mathrm{pH}_{\mathrm{pzc}}$ and the electrostatic adsorption process between the catalyst and the contaminant [20]. Jaafar et al. in a study entitled Nitrobenzene removal from aqueous solution using silver nanocatalyst coated on titanium dioxide under visible light in 2017 reported $\mathrm{pH}=5$ as the optimal $\mathrm{pH}$ [21]. Sonocatalytic degradation of 2-CP in the initial concentrations of 1 to $5 \mathrm{mg} \mathrm{L}^{-1}$ and catalyst dose of 0.05 to $1 \mathrm{~g} \mathrm{~L}^{-1}$ were investigated.

A significant increase in the degradation of 2-CP was observed by increasing the catalyst dosage up to about $0.8 \mathrm{~g} \mathrm{~L}^{-1}$, but at higher doses, the removal efficiency was almost negligible and constant in the end. Increasing the catalyst dose leads to an increase in active sites and subsequently improves surface cavitation, which enhances the production of free active radicals. Also, by increasing the catalyst dose, the collision probability will increase significantly. But at the same time, increasing doses of more than $0.8 \mathrm{~g} \mathrm{~L}^{-1}$ results in aggregation in the synthesized nanocomposite and reduce the active surfaces. In simpler terms, catalyst aggregation, inactivates the active surfaces responsible for various free radicals' production. Besides, overuse of the catalyst results in the scattering of ultrasound waves near the catalyst's surface, resulting in reduced sonocatalytic degradation (too much catalyst will prevent ultrasound waves from reaching all levels of the catalyst). By studying the degradation of 2-CP by $\mathrm{InVO}_{4} / \mathrm{TiO}_{2}$, Rashid et al. found that by increasing the dosage from 0.1 to $0.5 \mathrm{~g} \mathrm{~L}^{-1}$, the efficiency increased from $7.14 \%$ to $98 \%$ and then became constant [22].

Studying the effect of contaminant concentration on the degradation efficiency showed that the removal efficiency is inversely proportional to the initial concentration of 2-CP. By increasing the concentration from 1 to $5 \mathrm{mg} \mathrm{L}^{-1}$, the degradation efficiency decreased from 98 to $46 \%$. The explanation for this behavior could be that as the contaminant's initial concentration increased, the number of 2-CP molecules adsorbed on the catalyst surface increased. Therefore, there was a need for plenty of hydroxyl free radicals for contaminant degradation. Since the number of hydroxyl radicals, ultrasonic propagation power, and catalyst dose is constant against the increase of pollutants, the efficiency was decreased. On the other hand, due to the degradation of 2-CP, the production of by-products is predictable. The higher the concentration of the pollutant, the higher the output of degraded byproducts. Increasing the number of by-products will consume free radicals, which will negatively impact the efficiency. AjitSharma and Ba-Abbad in the study of removal of nitrobenzene with activated carbon synthesized from sludge, reported similar results to the present study [2][23]. The power of ultrasonic waves is another critical factor in the process of sonocatalytic degradation.

The removal efficiency has increased significantly with increasing power from 25 to $100 \mathrm{~W}$. The highest degradation efficiency was achieved at $81 \mathrm{~W} / \mathrm{L}$. Still, the costly production of this amount of power and, on the other hand, the tiny difference between the efficiency at 80 and $60 \mathrm{~W} / \mathrm{L}$ resulted in choosing $60 \mathrm{~W}$ as the optimal power of the degradation process. Increased production of hydroxyl radicals, increased diffusion, mass transfer, and improvements such as cavitation in the reactor, were some of the reasons for increasing the efficiency of the system at higher ultrasound power. Some researchers have reported that as ultrasonic waves' power increases, the cavitation energy, or energy required to produce air-filled bubbles (cavitation), also increases, leading to a rise in the quality and quantity of cavitation bubbles. Increasing the quantity and quality of air bubbles and increasing the reaction/contact between the contaminant and the catalyst during the explosion of air bubbles, also causes an increase in ambient temperature. Increasing the temperature affects the degradation efficiency in two ways. One is expanding the solubility of 2-CP, followed by increasing the effective collisions between the degradable material and the catalyst. The other is increasing the pore size on the catalyst surface, which leads to increased adsorption and degradation of the contaminant [24].

\subsection{Statistical study of the degradation process parameters effect}

Nowadays, statistical design methods and providing logical relation between variables are widely used in many research fields. Using statistical methods will reduce the number of experiments and consequently reduce costs and manpower. Using the studied statistical method, the following coded equation was obtained, which shows an experimental relation between the variables and efficiency percentage:

Page $7 / 21$ 
$\mathrm{Y}($ Removal \% $)=84-15(\mathrm{X} 1)+7.50(\mathrm{X} 2)-6.31(\mathrm{X} 3)+3.75(\mathrm{X} 4)+0.3750(\mathrm{X} 1 \times \mathrm{X} 2)+2.12(\mathrm{X} 1 \times \mathrm{X} 3)+$ $6.63(\mathrm{X} 1 \times \mathrm{X} 4)+1.12(\mathrm{X} 2 \times \mathrm{X} 3)+0.1250(\mathrm{X} 2 \times \mathrm{X} 4)-3.87(\mathrm{X} 3 \times \mathrm{X} 4)-6.94(\mathrm{X} 1)^{2}-3.69(\mathrm{X} 2)^{2}-7.44(\mathrm{X} 3)^{2}$ $-4.06(\mathrm{X} 4)^{2}$

$\mathrm{X} 1, \mathrm{X} 2, \mathrm{X} 3$, and $\mathrm{X} 4$ are $\mathrm{pH}$, catalyst dose, contaminant concentration, and ultrasound wavelength. The effect of the studied parameters on the degradation efficiency of nitrobenzene was assessed by analysis of variance (ANOVA) and results are presented in Table 4. The value of R-squared= 0.9966 and Adj R-Squared $=0.9886$ confirms that the designed model can well describe the degradation of 2-CP by magnetic titanium dioxide. The present study's F-value was 125.42 , which shows the ability to analyze the selected model in data analysis properly. Low CV (coefficient of variation less than 3.04) also confirms the model's suitability for interpreting the process. Adequate precision is a parameter that expresses the signal-to-noise ratio. If its value is more than 4, it shows the appropriate relationship between the laboratory and calculated results (desirability). In this study, the mentioned parameter was 38.36. Then, the effect of effective variables on the degradation process was studied using analysis of variance. Results showed that $X 1, X 2, X 3, X 4, X 1 X 3, X 1 X 4, X 3 X 4, X 1^{2}, X 2^{2}, X 3^{2}, X 4^{2}$ had some significant effects on the $2-C P$ degradation. Sum of squared and F-value showed that $\mathrm{pH}>$ contaminant concentration> catalyst dosage> Ultrasonic wavelength, respectively had the most effect of 2-CP degradation. The lack of fit parameter is another output data of the studied model. This parameter's non-significance is another evidence of the proper performance of the selected model for interpreting the data and a good reason for its accuracy. It is necessary to examine the normality of the studied data and the rest of the data as two critical assumptions for using the statistical model. The normal probability diagram of the data around the mean and the linear shape of this diagram shows the test data's normality. The normal plot obtained R-squared $=0.942$. The normality test of the output data and residuals can be seen in Fig. $\mathbf{3 a}$. The residuals histogram has a bell shape that confirms the normality of the data (Fig. $\mathbf{3 b}$ ). The p-value in the residual linear normality analysis is very small and close to zero, which means that the residuals are normal.The equation in terms of coded factors can be used to make predictions about the response for given levels of each factor. By default, the high levels of the factors are coded as +1 and the low levels are coded as -1 . The coded equation is useful for identifying the relative impact of the factors by comparing the factor coefficients.

Table 4. Results of the analysis of variance (ANOVA) for the studied model 


\begin{tabular}{|c|c|c|c|c|c|c|}
\hline Factors & Sum of Squares & df & Mean Square & F Value & p-value & \\
\hline Model & 7316.009 & 14 & 522.5721 & 125.4173 & $3.27 \mathrm{E}-06$ & Significant \\
\hline $\mathrm{X1}: \mathrm{pH}$ & 1800 & 1 & 1800 & 432 & 8.07E-07 & Significant \\
\hline X2: Catalyst dose & 450 & 1 & 450 & 108 & 4.65E-05 & Significant \\
\hline X3: Concentration 2 -Chlorophenol & 637.5625 & 1 & 637.5625 & 153.015 & $1.70 \mathrm{E}-05$ & Significant \\
\hline X4: Ultrasound power & 112.5 & 1 & 112.5 & 27 & 0.002022 & Significant \\
\hline $\mathrm{X} 1 \mathrm{X} 2$ & 0.5625 & 1 & 0.5625 & 0.135 & 0.725915 & Not Significant \\
\hline $\mathrm{X} 1 \mathrm{X3}$ & 36.125 & 1 & 36.125 & 8.67 & 0.025797 & Significant \\
\hline $\mathrm{X} 1 \mathrm{X} 4$ & 175.5625 & 1 & 175.5625 & 42.135 & 0.000636 & Significant \\
\hline$x 2 X 3$ & 10.125 & 1 & 10.125 & 2.43 & 0.170047 & Not Significant \\
\hline$X 2 X 4$ & 0.0625 & 1 & 0.0625 & 0.015 & 0.906523 & Not Significant \\
\hline X3X4 & 120.125 & 1 & 120.125 & 28.83 & 0.001713 & Significant \\
\hline$X 1^{2}$ & 1207.941 & 1 & 1207.941 & 289.9059 & $2.63 \mathrm{E}-06$ & Significant \\
\hline$x 2^{2}$ & 341.2745 & 1 & 341.2745 & 81.90588 & 0.000102 & Significant \\
\hline$x 3^{2}$ & 1388.333 & 1 & 1388.333 & 333.2 & $1.74 \mathrm{E}-06$ & Significant \\
\hline$X 4^{2}$ & 414.2157 & 1 & 414.2157 & 99.41176 & $5.89 \mathrm{E}-05$ & Significant \\
\hline Residual & 11.25 & 1 & 1.88 & & & \\
\hline Lack of Fit & 6.15 & 2 & 3.08 & 2.41 & 0.2055 & Not Significant \\
\hline Pure Error & 5.10 & 4 & 1.27 & & & \\
\hline Std. Dev. & 2.04 & & R-Squared & 0.9966 & & \\
\hline Mean & 67.14 & & Adj R-Squared & 0.9886 & & \\
\hline C.V. \% & 3.04 & & Adeq Precision & 38.366 & & \\
\hline
\end{tabular}

\subsection{Prediction of the degradation process by the studied software}

Fig. 4 shows the degradation prediction diagram of the 2-CP versus the actual amount (laboratory conditions) in various runs. Rsquare of 0.9982 and adjusted R-square of 0.9984 of the degradation prediction results of 2-CP were obtained by the studied model. Moreover, SSE and RMSE errors were obtained 24.91 and 1.145, respectively. Results showed a strong prediction ability of the model. Great matching of blue dots (actual amount) on the red line (predicted amount) confirms MATLAB's high ability to predict test results in different test runs. Also, the amount of R-square and adjusted R-square is very high, and the low amount of SSE and RMSE statistically confirms the predictive power of the pollutant degradation process in the studied system according to different runs. Following the study, using linear regression analysis, laboratory results were plotted and matched against the predicted results. As predicted, the R-square amount resulted from the regression is very close to 1 (Fig. $\mathbf{4 b}$ ), which is consistent with the previous results. The R-square value of 0.9983 indicates that less than $0.2 \%$ of the data cannot be predicted with the model.

\subsection{Optimization of the degradation process by the studied software}

Optimization of the process conditions is a requirement of presenting any statistical model. In this study, Genetic Algorithm (GA) was applied to optimize the degradation process of 2-CP. In this model, all errors were reduced to the lowest possible level and the 
best conditions were provided for the removal of 2-CP. The range of all studied parameters was assigned between their minimum and maximum range and the target parameter (degradation percentage \%) was set to maximize. According to these conditions, the software sets the available parameters to achieve the maximum possible degradation. Fig. $\mathbf{5}$ and Table $\mathbf{5}$ show the optimization results of the 2-CP degradation. As it is evident, with the increase of generations, the compatibility of these two graphs has increased. In the generation number 79, the amount of best and mean efficiencies is on top of each other, and no mutation is found in it. The distance between each generation is also presented in Fig. 5. As expected, by increasing the number of Generations, the average distance between them has decreased. In the 79th generation, this distance has reached close to zero. After determining the best generation, it is time to identify the most effective factors in the study. According to Fig. 5 and

Table 5, it can be reported that $\mathrm{pH}$, catalyst dosage, contaminant concentration, and ultrasound waves of $4.413,0.733 \mathrm{~g} \mathrm{~L}^{-1}, 2.549$ $\mathrm{mg} \mathrm{L}^{-1}$ and $55.605 \mathrm{w} \mathrm{L}^{-1}$, respectively are the optimal conditions for the degradation of 2-CP by the $\mathrm{M}-\mathrm{TiO}_{2}-\mathrm{US}$ system. To evaluate the genetic algorithm's ability to optimize the conditions, all the results obtained by the algorithm were repeated in the laboratory (real terms), and very close results were obtained. As shown in the table, under optimal conditions, the genetic algorithm's efficiency is equal to $97.776 \%$, and its laboratory rate is equal to $98.03 \%$.

Table 5. The results of GA and the efficiency of degradation in predicted and actual conditions

\begin{tabular}{|lllllll|}
\hline Factor & Range & $\begin{array}{l}\text { The lowest } \\
\text { range }\end{array}$ & $\begin{array}{l}\text { The highest } \\
\text { range }\end{array}$ & $\begin{array}{l}\text { Factor } \\
\text { importance }\end{array}$ & $\begin{array}{l}\text { Optimal } \\
\text { model } \\
\text { conditions }\end{array}$ & $\begin{array}{l}\text { Optimal laboratory } \\
\text { conditions }\end{array}$ \\
\hline $\mathrm{X} 1$ & $\begin{array}{l}\text { Case } \\
\text { study }\end{array}$ & 3 & 11 & 3 & 4.413 & 4.413 \\
\hline X2 & $\begin{array}{l}\text { Case } \\
\text { study }\end{array}$ & 0.05 & 1 & 3 & 0.733 & 0.733 \\
\hline X3 & $\begin{array}{l}\text { Case } \\
\text { study }\end{array}$ & 1 & 5 & 3 & 2.549 & 2.549 \\
\hline X4 & $\begin{array}{l}\text { Case } \\
\text { study }\end{array}$ & 25 & 100 & 3 & 55.605 & 55.605 \\
\hline Y & Maximize & 0 & 100 & 3 & 97.776 & 98.03 \\
\hline
\end{tabular}

Fig. 6 shows the contribution percentage of the primary test factors to the degradation of 2-CP. As it can be seen, $x 1$ and $x 3$ factors have a negative effect on the efficiency, and $x 2$ and $x 4$ factors have a positive effect on the efficiency. When $x 1$ increases from 4.84 to 11 , the efficiency will almost decrease between 60 to $70 \%$. In X3, X2, and X4 cases, by increasing their amount from 0.05 to $0.7625,2.56$ to 5 , and 25 to 71.5 , the efficiency increases between the ranges of 30 to $40 \%, 40$ to $50 \%$ and 20 to $30 \%$, respectively. The results are interestingly consistent with the optimization results by genetic algorithm and show that the parameter $\mathrm{X} 1$ or $\mathrm{pH}$ is the most effective factor in the removal of 2-CP.

\subsection{Kinetics study}

Fig. 7 shows the efficiency variations at different times of the degradation process. Removal efficiency changes after 10 min are negligible. Therefore, $10 \mathrm{~min}$ was reported as the optimal time. In the second part of the diagram, the first-order kinetics 2-CP degradation under optimized conditions were studied. R-square of $>0.97$, adjusted R-square of $>0.96$, SSE of 0.4653 , and RMSE of 0.3051 indicated a great fit of the degradation process with the first-order kinetic model. By increasing the time of up to $10 \mathrm{~min}$, the degradation properly happened and then it has been decreased. The increase in degradation efficiency in the early stages of the process is probably due to the fresh catalyst surface and the high ability to produce free radicals by $\mathrm{M}^{-\mathrm{TiO}_{2}}$. Over time, the catalyst surface becomes less capable of producing free radicals. On the other hand, at the beginning of the process, the target contaminant is only 2-CP, but over time and with the free radicals colliding with the pollutant, intermediate products will be produced to consume the generated free radicals, which is also one of the effective factors in minor changes in efficiency after 10 minu. As mentioned in the degradation kinetics, the high rate of R-square and adjusted R-square coefficients and the low error coefficients of SSE and RMSE is a strong reason for the 2-CP degradation process to follow the first-order kinetics. The 
degradation constant rate $\left(\mathrm{k}_{\mathrm{app}}\right)$ of 2-CP by $\mathrm{M}-\mathrm{TiO}_{2}$ was $0.3207 \mathrm{~min}^{-1}$, which was higher than Nidhi Sharotri, Muzammil Anjum, and Jih-Gawlin studies concerning the degradation of 2-CP by nitrogen-doped $\mathrm{TiO}_{2}, \mathrm{ZnO}-\mathrm{ZnS} @$ polyaniline, and ultrasound/ $\mathrm{H}_{2} \mathrm{O}_{2}$, indicating excellent performance of the system in the present study [6][25][26]

\subsection{Degradation mechanism and TOC analysis}

The degradation mechanism of the synthesized M-TiO2 under ultrasound propagation is presented in equations 4 to 9 .

$$
\begin{aligned}
& \mathrm{M}-\mathrm{TiO}_{2}+\text { ultrasound waves } \rightarrow \mathrm{Fe}_{3} \mathrm{O}_{4}\left(\mathrm{~h}^{+} . \mathrm{e}^{-}\right)-\mathrm{TiO}_{2} \\
& \mathrm{Fe}_{3} \mathrm{O}_{4}\left(\mathrm{~h}^{+} \cdot \mathrm{e}^{-}\right)-\mathrm{TiO}_{2} \rightarrow \mathrm{Fe}_{3} \mathrm{O}_{4}\left(\mathrm{~h}^{+}\right)-\mathrm{TiO}_{2}\left(\mathrm{e}^{-}\right) \\
& \mathrm{TiO}_{2}\left(\mathrm{e}^{-}\right)+\mathrm{O}_{2} \rightarrow \mathrm{O}_{2}^{\circ-}+\mathrm{TiO}_{2} \\
& \mathrm{Fe}_{3} \mathrm{O}_{4}\left(\mathrm{~h}^{+}\right)+\mathrm{OH}^{-} \rightarrow \mathrm{OH}^{\circ} \\
& \mathrm{h}^{+}+\mathrm{H}_{2} \mathrm{O} \rightarrow \mathrm{OH}^{\circ}+\mathrm{h}^{+} \\
& \mathrm{h}^{+}+\mathrm{OH}^{\circ}+\mathrm{O}_{2}^{\circ-}+2-\mathrm{CP} \rightarrow \mathrm{CO} 2+\mathrm{H} 2 \mathrm{O}
\end{aligned}
$$

As shown in Equations 4 to 9, superoxide and hydroxyl free radicals are mainly produced by the collision of US waves with MTiO2. The presence of these two free radicals plays a significant role in the degradation of 2-CP. Then, TOC analysis was performed for the mineralization of pollutants by the M-TiO2-US system under optimal conditions. Despite $98 \%$ removal efficiency of 2-CP, only a $61 \%$ reduction in TOC was observed. This can be due to the presence of intermediates with higher resistance and more laborious destruction than the primary contaminant. In addition to the degradation of 2-CP, Free radicals are used to degrade by-products, which results in a reduction in TOC's removal efficiency.

\subsection{Regeneration}

Regeneration of the synthesized catalyst was studied under optimum conditions. In each step, the catalyst nanocomposite was extracted from the solution by a magnet, washed several times with water and ethanol, and dried to use for the next step.

As shown in Fig. 8, sonocatalytic degradation efficiency of 2-CP after five consecutive replications are 98, 94, 90, 86, and 85.96\%, respectively. This evidence shows that $\mathrm{M}-\mathrm{TiO}_{2}$ nanocomposite has excellent durability and adequate degradation power of 2-CP up to five times. The decrease in catalyst efficiency during 5 steps may be because of the catalyst destruction by intermediates or the adsorption of them to the catalyst's surface and subsequent blockage of catalyst active sites. Catalyst washing and drying processes may also reduce some of the catalyst capacity.

\section{Conclusion}

$\mathrm{M}-\mathrm{TiO}_{2}$ with an average size of less than $100 \mathrm{~nm}$ was used as a reusable sono-catalyst effective in degrading 2-CP. The removal efficiency of 2-CP and TOC by the M-TiO2-US system was 98 and $61 \%$, respectively. The primary mechanism in the degradation of $2-\mathrm{CP}$ by the investigated system was producing significant amounts of hydroxyl and superoxide radicals. The reusability study showed that the removal efficiency of 2 -CP was reduced by $12 \%$ after five repetitions. Given the promising results of this study, further research should be done on the use of the $\mathrm{M}-\mathrm{TiO}_{2}$-US system for the degradation of other organic pollutants in water and wastewater.

\section{Declarations}

\section{Conflict of Interest}

The authors declare that they have no conflict of interest.

\section{Acknowledgment}


This research has been done with the financial support of Bushehr University of Medical Sciences with project code 4324 . The authors of this article are grateful for the help and sincere cooperation of Bushehr University of Medical Sciences. The cooperation of the Presidential Nano Headquarters is also commended.

\section{References}

[1] M. Pera-Titus, V. García-Molina, M.A. Baños, J. Giménez, S. Esplugas, Degradation of chlorophenols by means of advanced oxidation processes: A general review, Appl. Catal. B Environ. 47 (2004) 219-256. https://doi.org/10.1016/j.apcatb.2003.09.010.

[2] A. Sharma, B.K. Lee, Rapid photo-degradation of 2-chlorophenol under visible light irradiation using cobalt oxide-loaded TiO2/reduced graphene oxide nanocomposite from aqueous media, J. Environ. Manage. 165 (2016) 1-10. https://doi.org/10.1016/j.jenvman.2015.09.013.

[3] I.A. Mkhalid, Visible Light Photocatalytic Degradation of 2-Chlorophenol in Wastewater Using Copper Selenide Nanorods, Nanosci. Nanotechnol. Lett. 8 (n.d.) 744-749. https://www.ingentaconnect.com/content/asp/nnl/2016/00000008/00000009/art00008.

[4] G. Darabdhara, P.K. Boruah, P. Borthakur, N. Hussain, M.R. Das, T. Ahamad, S.M. Alshehri, V. Malgras, K.C.W. Wu, Y. Yamauchi, Reduced graphene oxide nanosheets decorated with Au-Pd bimetallic alloy nanoparticles towards efficient photocatalytic degradation of phenolic compounds in water, Nanoscale. 8 (2016) 8276-8287. https://doi.org/10.1039/c6nr00231e.

[5] L.G.C. Villegas, N. Mashhadi, M. Chen, D. Mukherjee, K.E. Taylor, N. Biswas, A Short Review of Techniques for Phenol Removal from Wastewater, Curr. Pollut. Reports. 2 (2016) 157-167. https://doi.org/10.1007/s40726-016-0035-3.

[6] N. Sharotri, D. Sud, Ultrasound-assisted synthesis and characterization of visible light responsive nitrogen-doped TiO2nanomaterials for removal of 2-Chlorophenol, Desalin. Water Treat. 57 (2016) 8776-8788. https://doi.org/10.1080/19443994.2015.1026278.

[7] M.Z. Ge, C.Y. Cao, J.Y. Huang, S.H. Li, S.N. Zhang, S. Deng, Q.S. Li, K.Q. Zhang, Y.K. Lai, Synthesis, modification, and photo/photoelectrocatalytic degradation applications of TiO2 nanotube arrays: A review, Nanotechnol. Rev. 5 (2016) 75-112. https://doi.org/10.1515/ntrev-2015-0049.

[8] I.A. Barbosa, L.D. Zanatta, D.M. Espimpolo, D.L. da Silva, L.F. Nascimento, F.B. Zanardi, P.C. de Sousa Filho, O.A. Serra, Y. lamamoto, Magnetic diatomite(Kieselguhr)/Fe2O3/TiO2 composite as an efficient photo-Fenton system for dye degradation, Solid State Sci. 72 (2017) 14-20. https://doi.org/10.1016/j.solidstatesciences.2017.08.007.

[9] Z. Ebrahimi, K. Hedayati, D. Ghanbari, Preparation of hard magnetic BaFe12019-TiO2 nanocomposites: applicable for photo-degradation of toxic pollutants, J. Mater. Sci. Mater. Electron. 28 (2017) 13956-13969. https://doi.org/10.1007/s10854017-7245-3.

[10] M.A. Golsefidi, B. Sarkhosh, Preparation and characterization of rapid magnetic recyclable Fe304@SiO2@TiO2-Sn photocatalyst, J. Iran. Chem. Soc. 14 (2017) 1089-1098. https://doi.org/10.1007/s13738-017-1058-4.

[11] S. Tabasideh, A. Maleki, B. Shahmoradi, E. Ghahremani, G. McKay, Sonophotocatalytic degradation of diazinon in aqueous solution using iron-doped TiO2 nanoparticles, Sep. Purif. Technol. 189 (2017) 186-192.

https://doi.org/10.1016/j.seppur.2017.07.065.

[12] A. Hassani, A. Khataee, S. Karaca, C. Karaca, P. Gholami, Sonocatalytic degradation of ciprofloxacin using synthesized TiO2 nanoparticles on montmorillonite, Ultrason. Sonochem. 35 (2017) 251-262.

https://doi.org/10.1016/j.ultsonch.2016.09.027. 
[13] P. Singh, M.C. Vishnu, K.K. Sharma, R. Singh, S. Madhav, D. Tiwary, P.K. Mishra, Comparative study of dye degradation using TiO2-activated carbon nanocomposites as catalysts in photocatalytic, sonocatalytic, and photosonocatalytic reactor, Desalin. Water Treat. 57 (2016) 20552-20564. https://doi.org/10.1080/19443994.2015.1108871.

[14] A. Esrafili, R.R. Kalantary, A.A.-... of M. Sciences, undefined 2016, Removal of diethyl phthalate from aqueous solution using persulfate-based (UV/Na2S208/Fe2+) advanced oxidation process, Jmums.Mazums.Ac.Ir. (n.d.).

http://jmums.mazums.ac.ir/files/site1/user_files_0d0bf0/nouri70-A-10-5029-165-70d4196.pdf (accessed July 21, 2020).

[15] A.A. Babaei, B. Kakavandi, A. Azari, R.R. Kalantary, Enhanced removal of nitrate from water using nZVI@MWCNTs composite: Synthesis, kinetics and mechanism of reduction, Water Sci. Technol. 72 (2015) 1988-1999. https://doi.org/10.2166/wst.2015.417.

[16] L. Tan, X. Zhang, Q. Liu, X. Jing, J. Liu, D. Song, S. Hu, L. Liu, J. Wang, Synthesis of Fe304TiO2 core-shell magnetic composites for highly efficient sorption of uranium (VI), Colloids Surfaces A Physicochem. Eng. Asp. 469 (2015) 279-286. https://doi.org/10.1016/j.colsurfa.2015.01.040.

[17] L. Tan, X. Zhang, Q. Liu, X. Jing, J. Liu, ... D.S.-C. and S.A., undefined 2015, Synthesis of Fe304@ TiO2 core-shell magnetic composites for highly efficient sorption of uranium (VI), Elsevier. (n.d.).

https://www.sciencedirect.com/science/article/pii/S0927775715000680 (accessed July 19, 2020).

[18] A. Azari, A.-A. Babaie, R. Rezaei-Kalantary, A. Esrafili, M. Moazzen, B. Kakavandi, Nitrate removal from aqueous solution by carbon nanotubes magnetized with nano zero-valent iron TT -, J-Mazand-Univ-Med-Sci. 23 (2014) 15-27. http://jmums.mazums.ac.ir/article-1-3089-en.html.

[19] B. Kakavandi, A. Jonidi Jafari, R. Rezaei Kalantary, S. Nasseri, A. Esrafili, A. Gholizadeh, A. Azari, Simultaneous adsorption of lead and aniline onto magnetically recoverable carbon: optimization, modeling and mechanism, J. Chem. Technol. Biotechnol. 91 (2016) 3000-3010. https://doi.org/10.1002/jctb.4925.

[20] J. Rashid, M.A. Barakat, Y. Ruzmanova, A. Chianese, Fe304/SiO2/TiO2 nanoparticles for photocatalytic degradation of 2chlorophenol in simulated wastewater, Environ. Sci. Pollut. Res. 22 (2015) 3149-3157. https://doi.org/10.1007/s11356-0143598-9.

[21] N. Jaafar, A. Jalil, S.T.-A.S. Science, undefined 2017, Visible-light photoactivity of plasmonic silver supported on mesoporous TiO2 nanoparticles (Ag-MTN) for enhanced degradation of 2-chlorophenol: Limitation, Elsevier. (n.d.). https://www.sciencedirect.com/science/article/pii/S0169433216319900? casa_token=EOQcLv2rbgQAAAAA:vFFxbLKvpx8rAunL0Qy4GwSfc5vEiyx4BG3U148Le-x-wozx-zloZmmAXHdB8X8hUwEV2pU5 (accessed July 21, 2020).

[22] J. Rashid, M.A. Barakat, S.L. Pettit, J.N. Kuhn, InVO4/TiO2 composite for visible-light photocatalytic degradation of 2chlorophenol in wastewater, Environ. Technol. (United Kingdom). 35 (2014) 2153-2159. https://doi.org/10.1080/09593330.2014.895051.

[23] M.M. Ba-Abbad, M.S. Takriff, A. Amir, H. Kadhum, A.B. Mohamad, A. Benamor, A. Wahab Mohammad, Solar photocatalytic degradation of 2-chlorophenol with $\mathrm{ZnO}$ nanoparticles: optimisation with D-optimal design and study of intermediate mechanisms, Springer. (n.d.). https://doi.org/10.1007/s11356-016-8033-y.

[24] A. Barik, P.G.-U. sonochemistry, undefined 2017, Degradation of 2, 4-dichlorophenol using combined approach based on ultrasound, ozone and catalyst, Elsevier. (n.d.). https://www.sciencedirect.com/science/article/pii/S1350417716302875? casa_token=cxHHzMCzBk8AAAAA:8yBys00tqOj-GBxjjcClujSi5hDQsvDNsysAtsUVcjLwBLiPmWf4wK-Nq7-WPWOJvRJROrQ1 (accessed July 21, 2020).

[25] M. Anjum, M. Oves, R. Kumar, \& M.B.-I.B., undefined 2017, Fabrication of ZnO-ZnS@ polyaniline nanohybrid for enhanced photocatalytic degradation of 2-chlorophenol and microbial contaminants in wastewater, Elsevier. (n.d.). 
https://www.sciencedirect.com/science/article/pii/S0964830516305285?

casa_token=LXI8iPPswaAAAAAA:R_YJoWm7pl3gObH6gxShuuWzN3lg91Soz0n2loMMOi8XAeVGHptR0ALPbsRYE3QkGKsF9NAQ (accessed July 21, 2020).

[26] J. Lin, C. Chang, J. Wu, Y.M.-W.S. and Technology, undefined 1996, Enhancement of decomposition of 2-chlorophenol with ultrasound/H2O2 process, Elsevier. (n.d.). https://www.sciencedirect.com/science/article/pii/S0273122396007858 (accessed July 21,2020$)$.

\section{Figures}
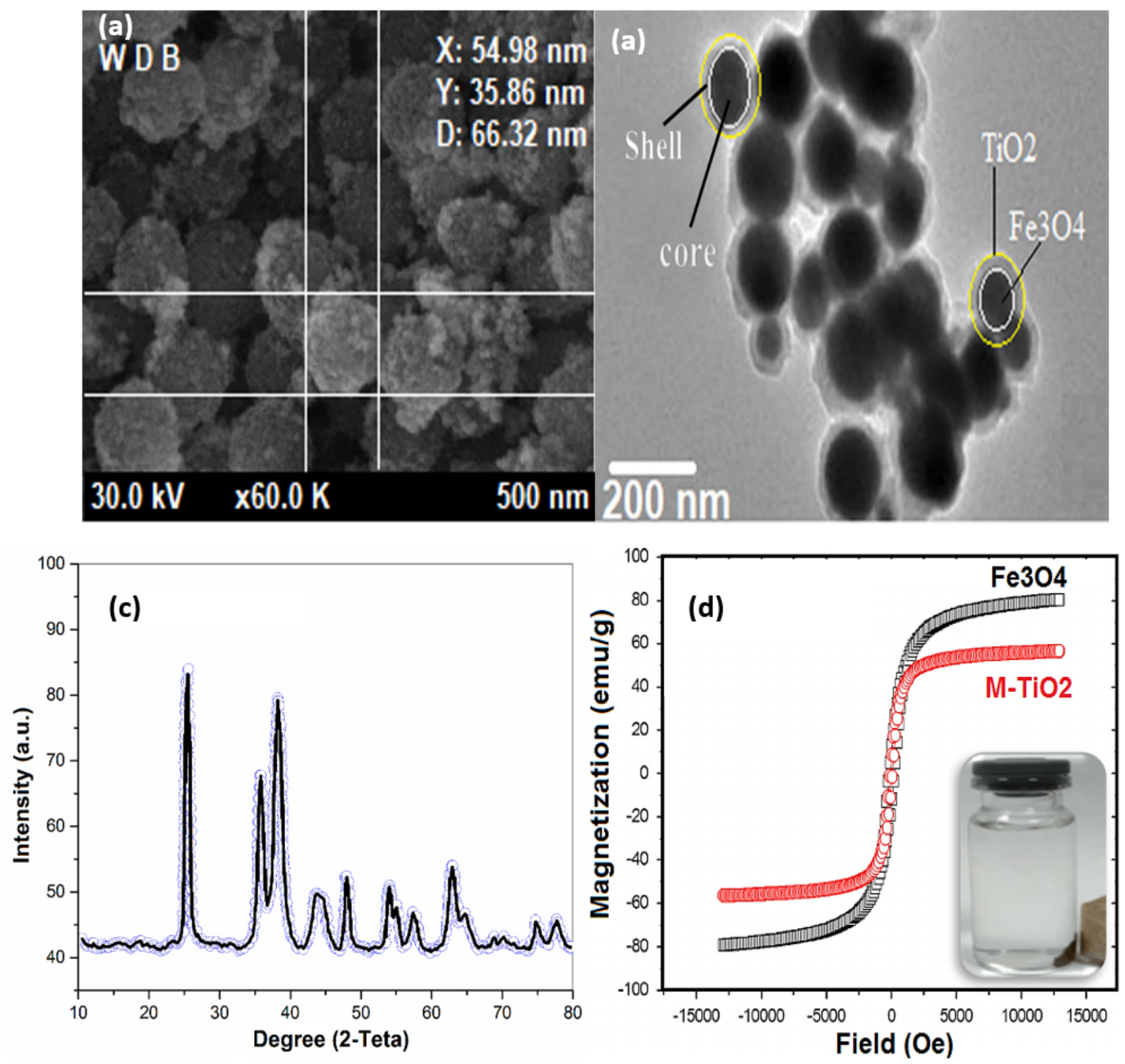

Figure 1

SEM (a), TEM (b), XRD pattern (c) and VSM analysis (d) of the synthesized composite 

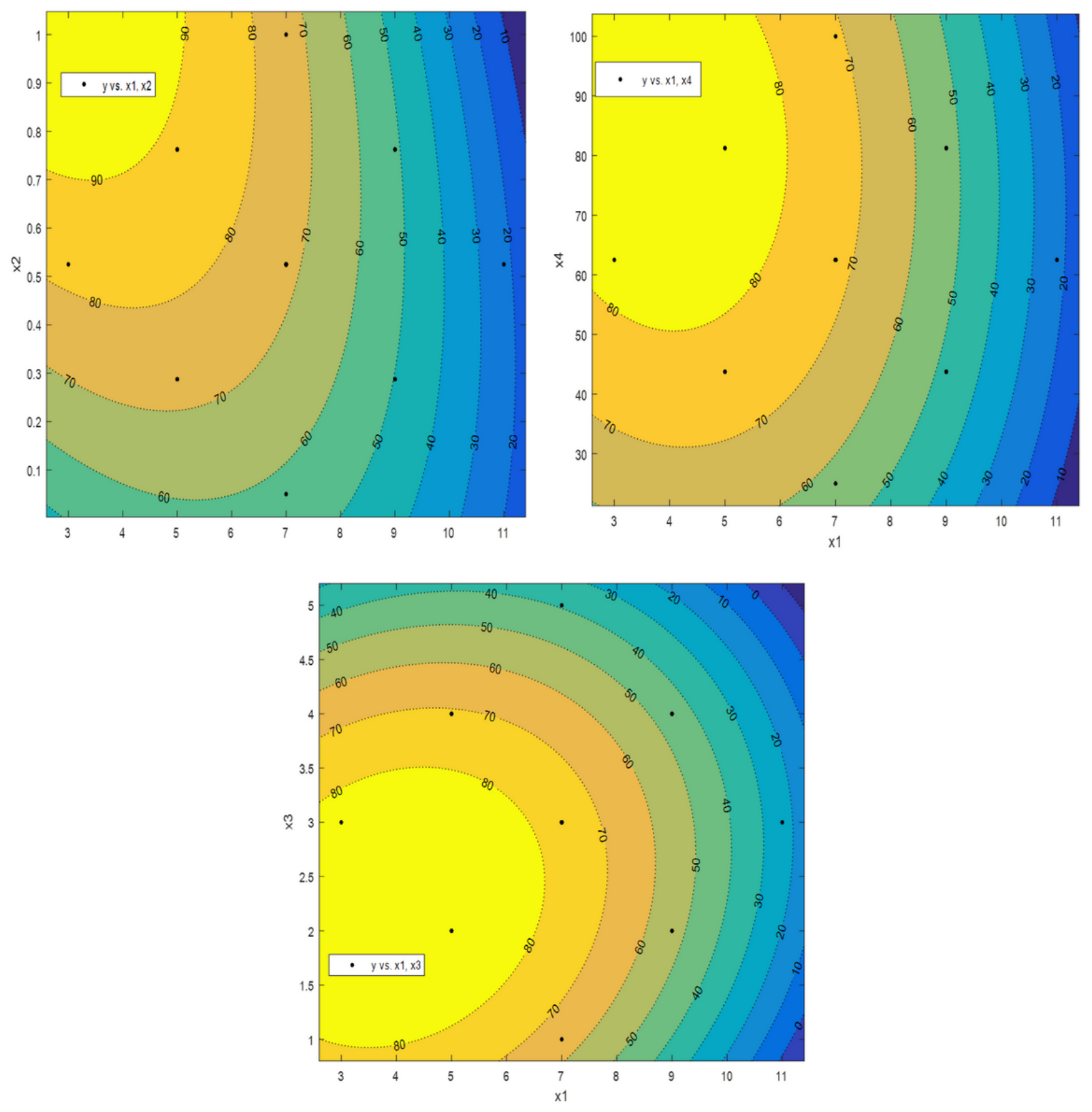

\section{Figure 2}

Effect of studied initial parameters in the degradation process ( $x 1$ to $x 4$ shows the $\mathrm{pH}$, catalyst dose, contaminant concentration, and ultrasound wavelength, respectively). 
(a)
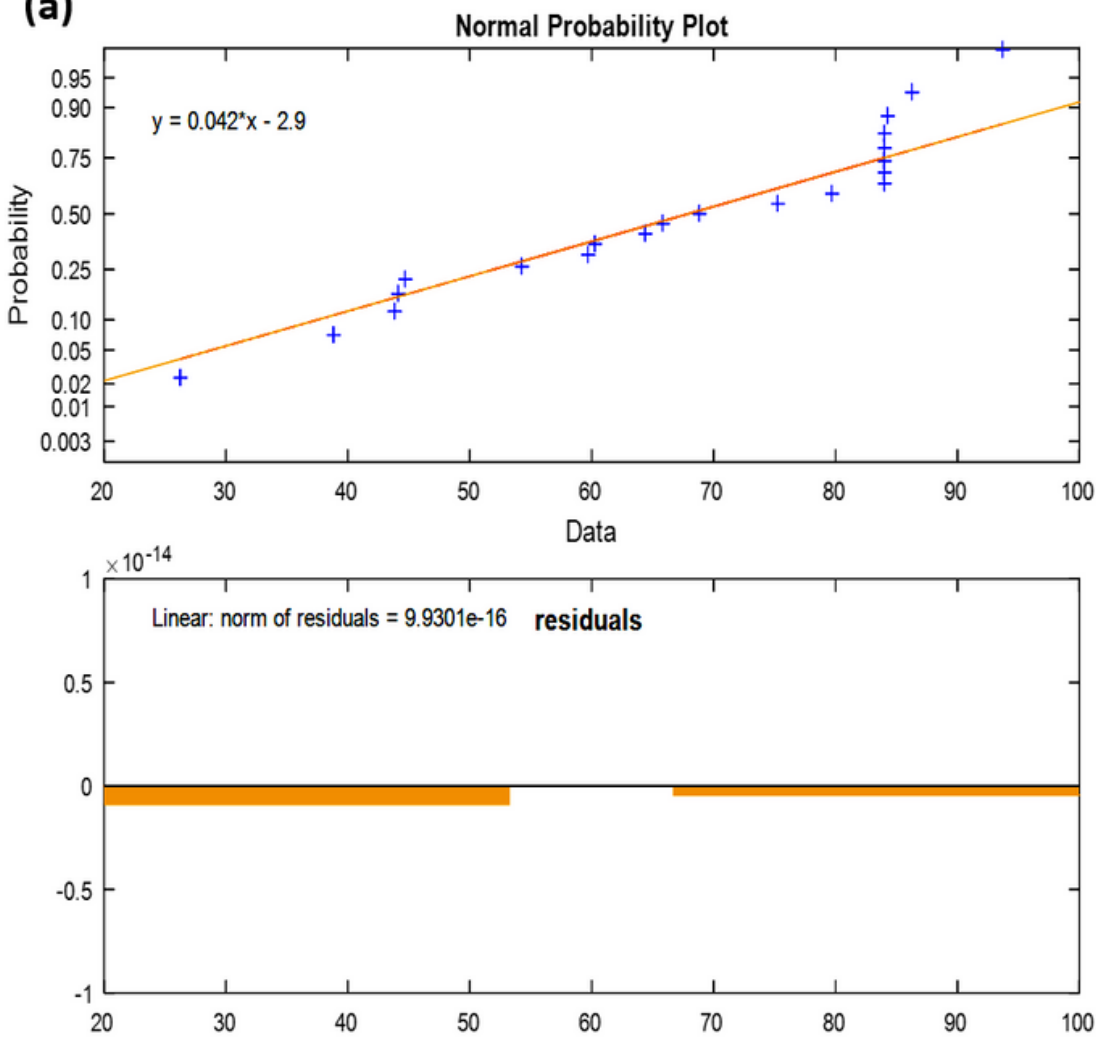

(b)

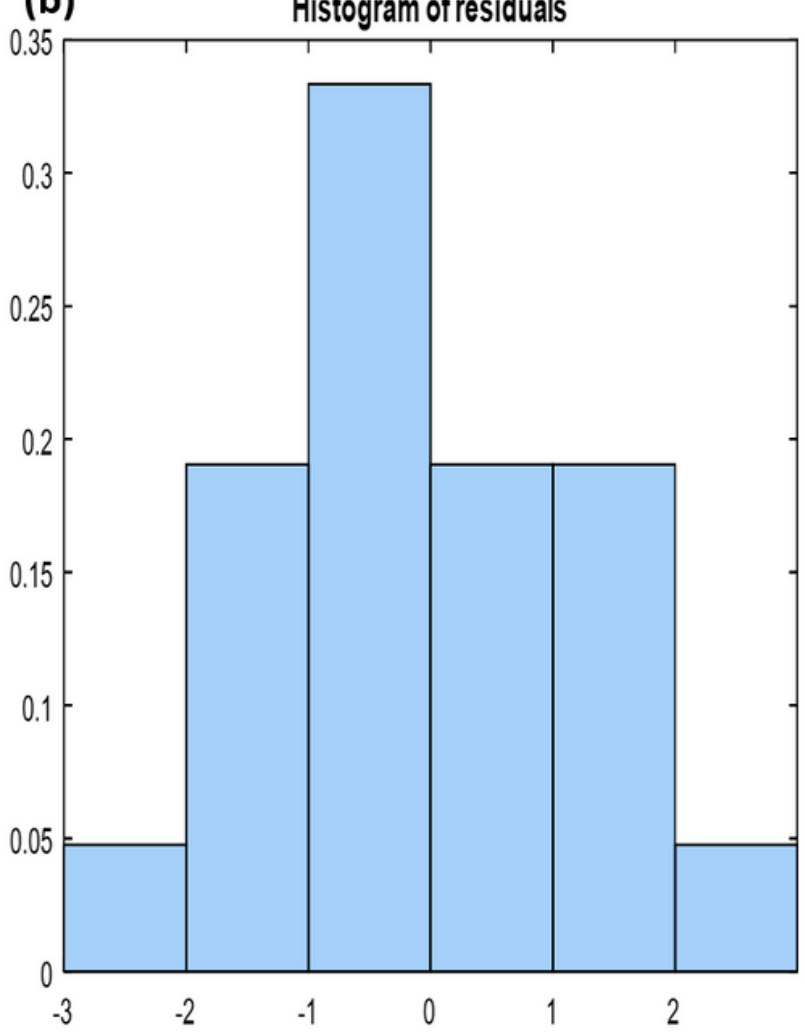

Figure 3

The normal probability diagram of the data (a), and Histogram plot of residuals(C) 

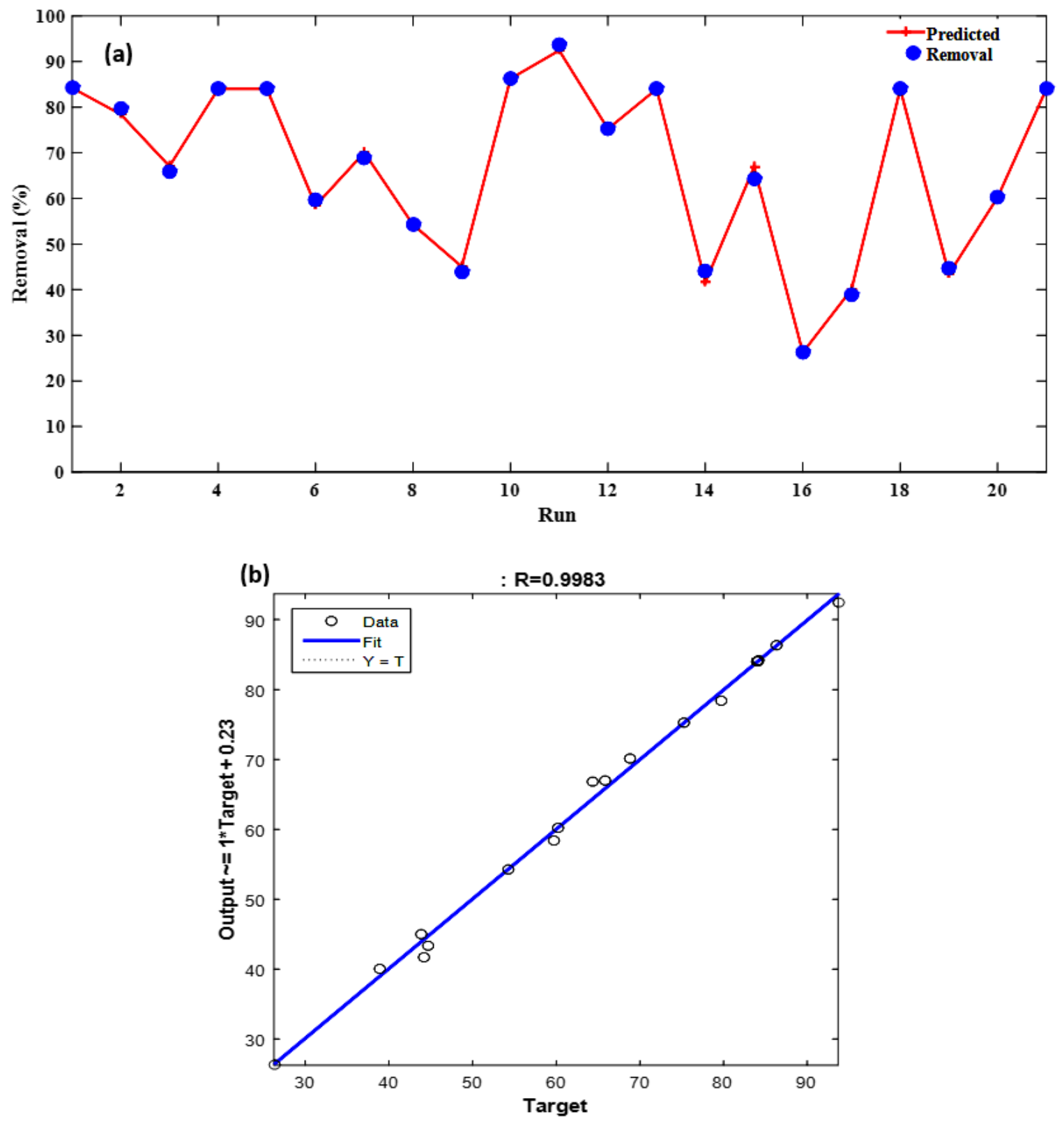

\section{Figure 4}

Prediction and the actual rate of efficiency in different test (a) and graph of the rate of laboratory results versus software prediction (b) 

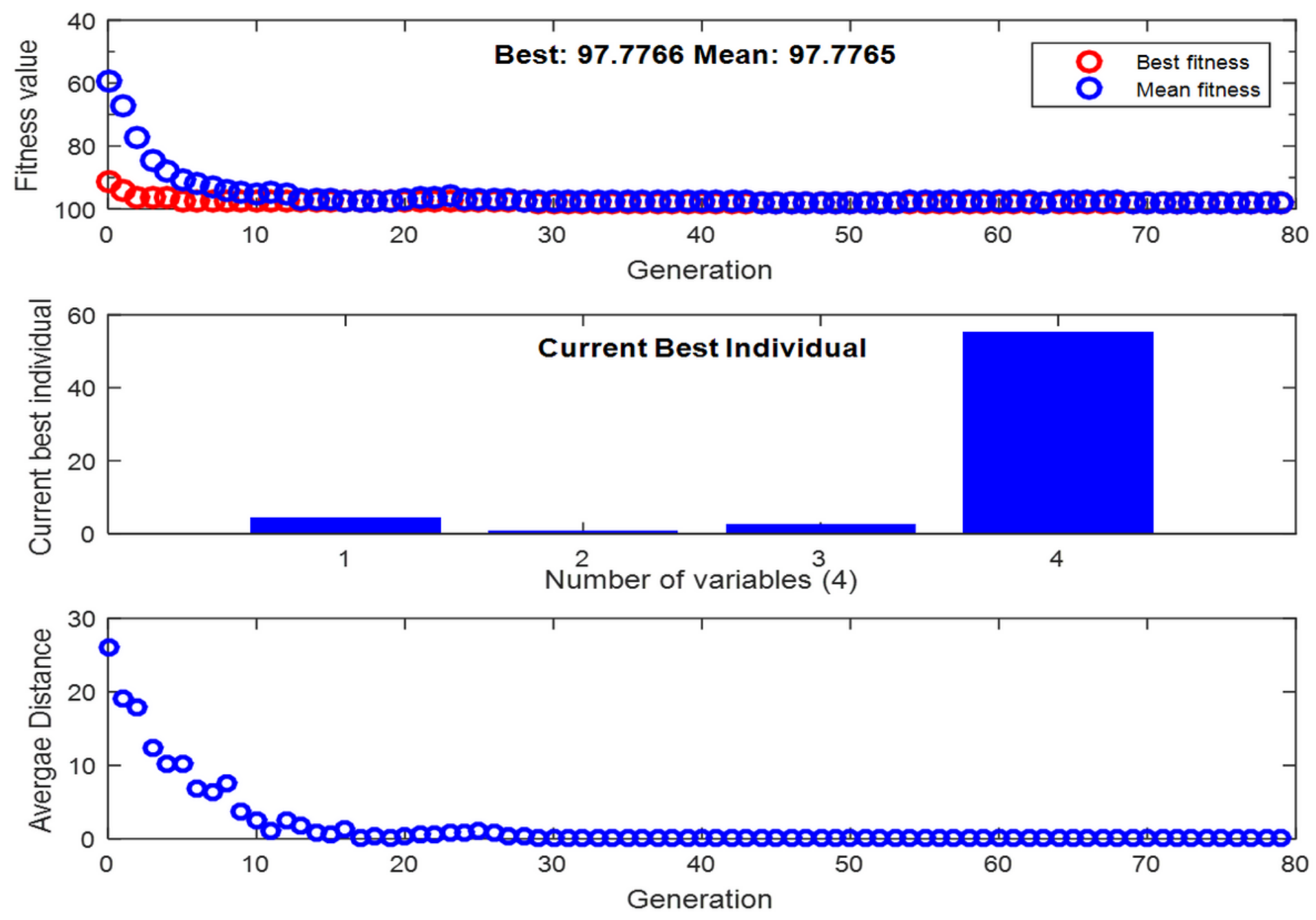

Figure 5

Optimization steps of the initial parameters of the degradation process using the genetic algorithm 


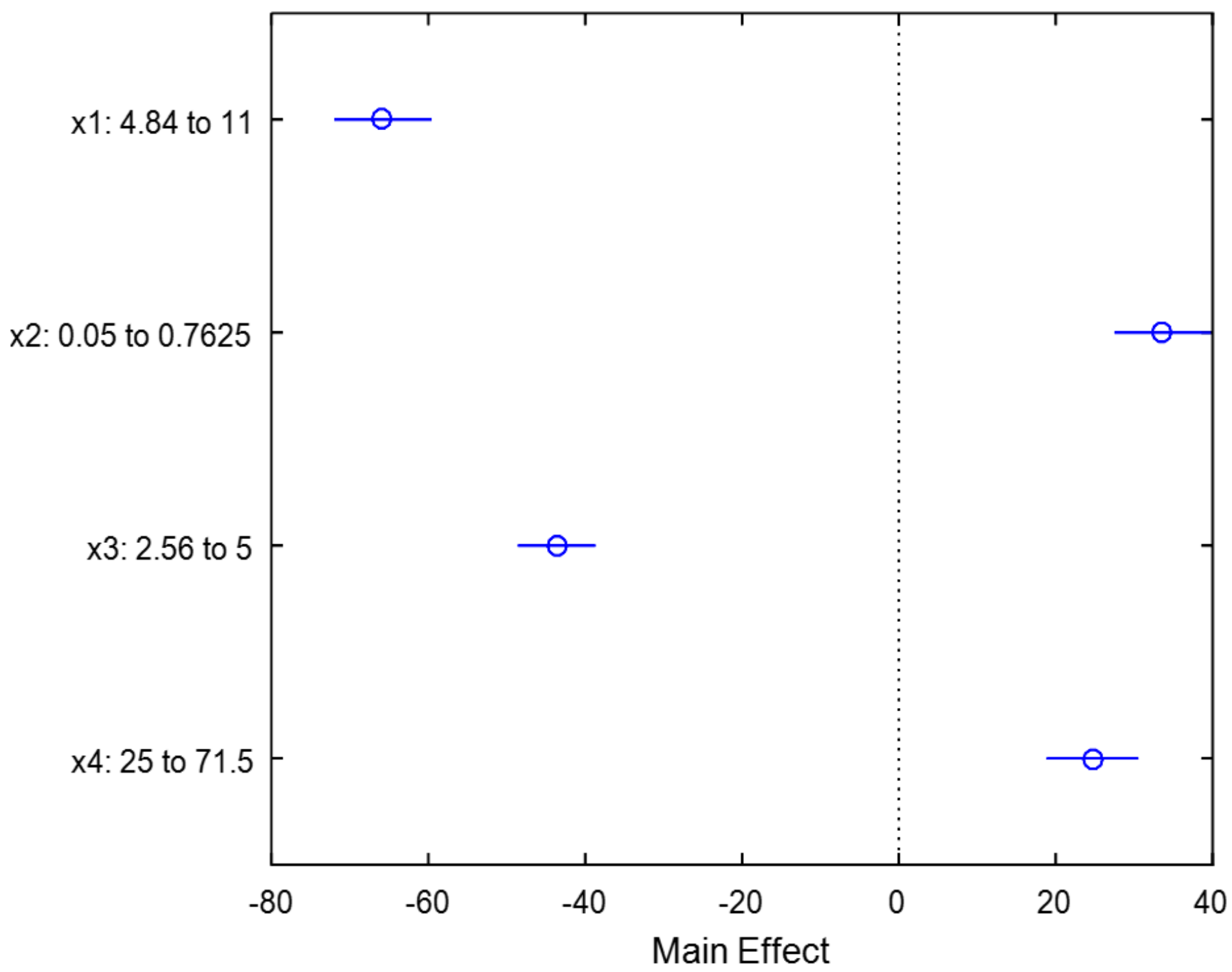

Figure 6

Percentage of participation of primary test factors in 2-chlorophenol degradation 


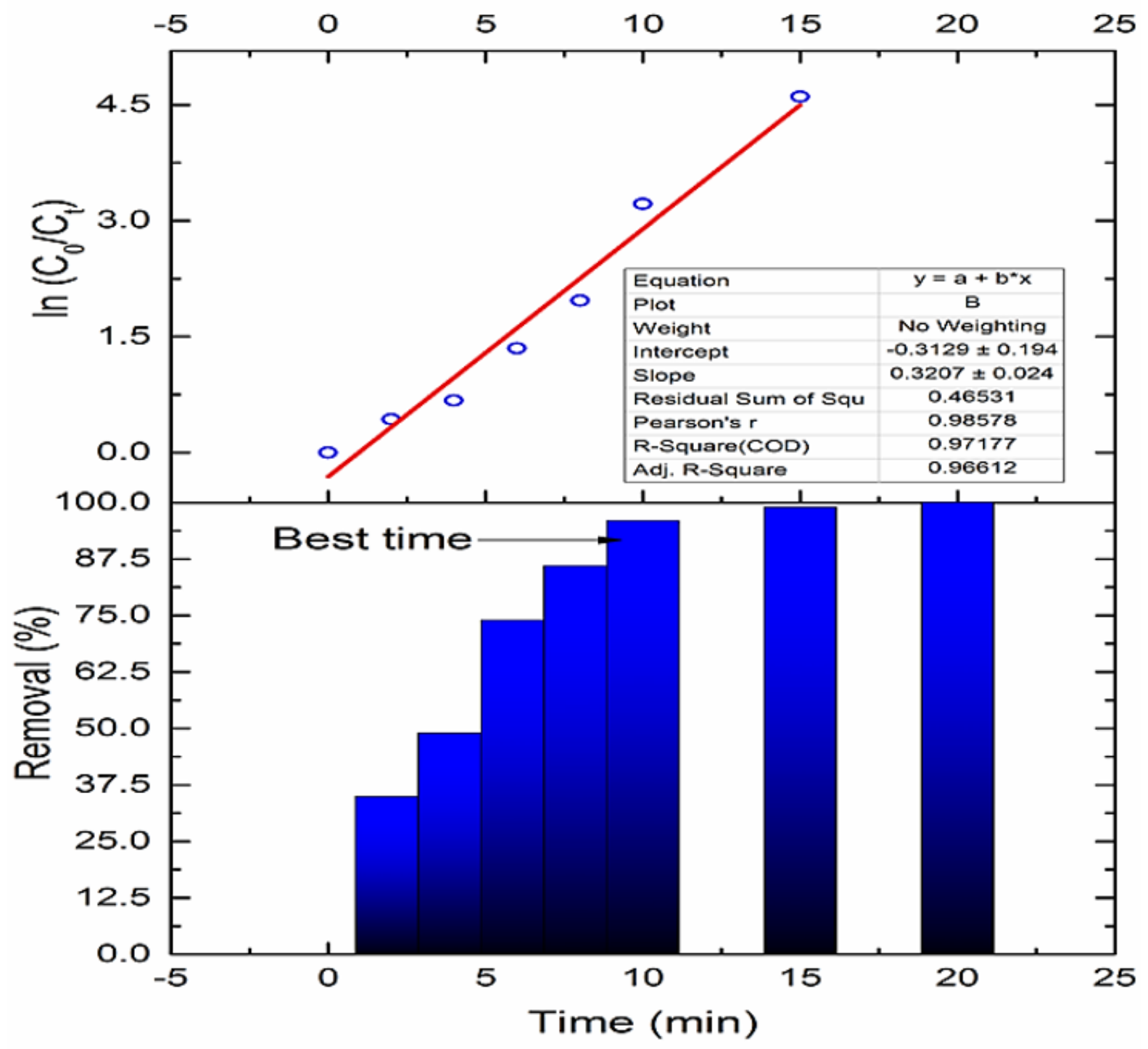

Figure 7

Investigating the effect of time on the degradation process and studying the process kinetics under optimal conditions 


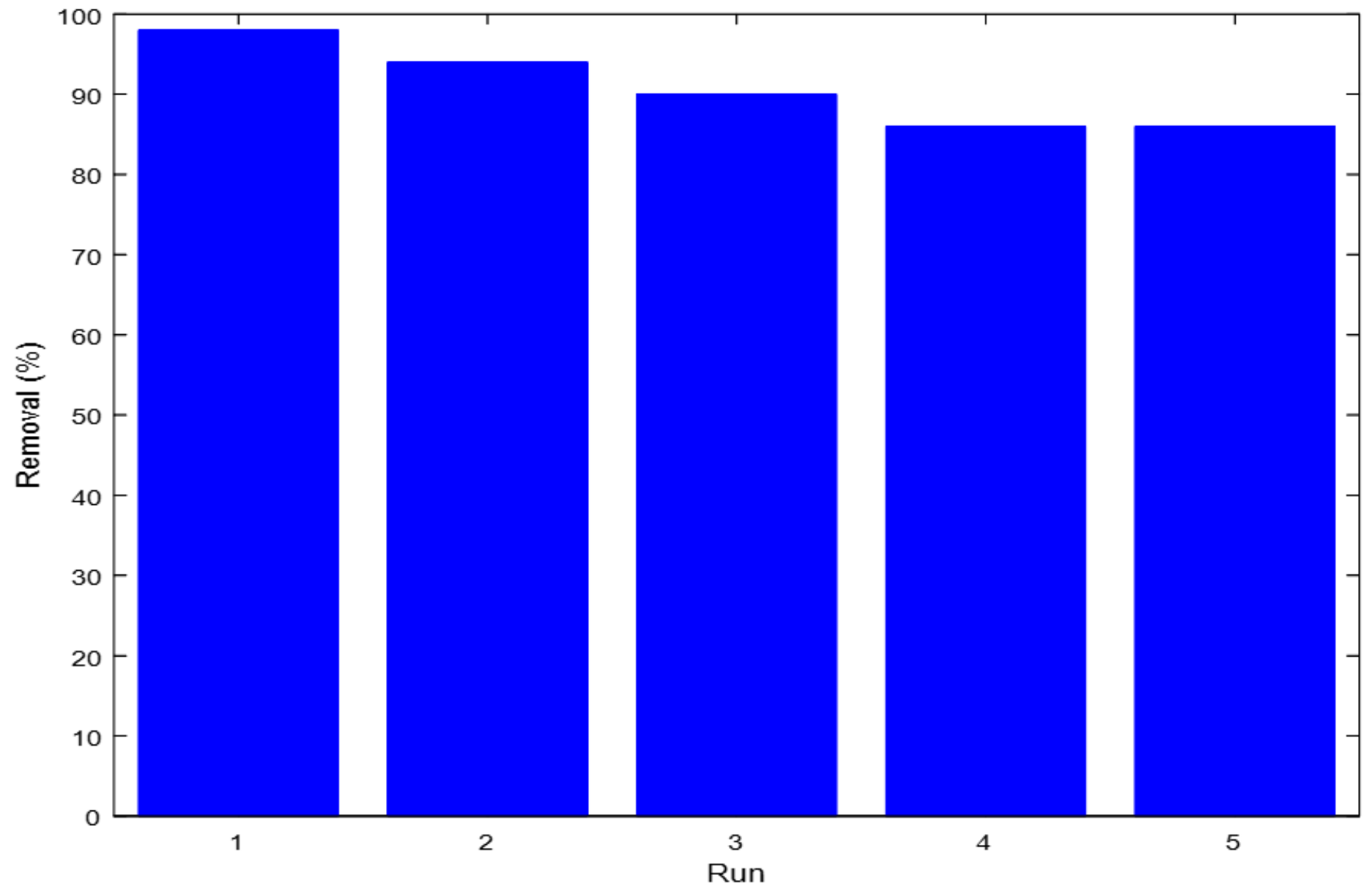

Figure 8

Regeneration of the synthesized catalyst under optimum conditions 